\title{
Pengolahan Sampah Organik Bank Sampah Pematang Pudu Bersih Kecamatan Mandau Kabupaten Bengkalis
}

\author{
Prama Widayat ${ }^{1}$, Ryan Pahlawan ${ }^{2}$ \\ 1,2Universitas Lancang Kuning, Pekanbaru, Indonesia \\ *Corresponding Author: pramawidayat@unilak.ac.id
}

\begin{abstract}
Info Artikel Diterima : 20/10/2021 Direvisi: 28/10/2021 Disetujui: 01/11/2021
Abstract. Mandau District is one of the most densely populated districts in Bengkalis Regency, here there is a Pematang Pudu Clean Waste Bank located in Pematang Pudu village with a population of 29,986 people consisting of $17 \mathrm{RW}$ and $95 \mathrm{RT}$ with an area of $25 \mathrm{Km}^{2}$. This waste bank was established in 2015 which accommodates non-organic waste such as bottles, plastic, paper and cardboard of various types. In addition, there is also organic waste such as leaves, fruit peels from traders around Pematang Pudu Village, but this has not been optimally processed due to limited capabilities and human resources. Even though the potential is quite large to encourage an increase in the income of the waste bank apart from non-organic waste. Therefore, organic waste processing is carried out with 2 models, namely using a starter or composter EM4 and M21, from these two processes it turns out to produce compost at the same time, neither is faster, which both take 30 calendar days.
\end{abstract}

Keywords: Organic waste, Waste bank, Compost

Abstrak. Kecamatan Mandau merupakan salah satu kecamatan yang cukup padat penduduk di Kabupaten Bengkalis, disini terdapat sebuah Bank Sampah Pematang Pudu Bersih yang berada pada kelurahan Pematang Pudu dengan jumlah penduduk 29.986 jiwa yang terdiri dari 17 RW dan 95 RT dengan luas wilayah $25 \mathrm{Km}^{2}$. Bank sampah ini berdiri sejak 2015 yang menampung sampah non-organik seperti botol, plastik, kertas dan karton dengan beragam jenis. Selain itu juga terdapat sampah organik seperti daundaunan, kulit buah-buahan dari pedagang sekitar Kelurahan Pematang Pudu, namun hal ini belum maksimal untuk diolah karena keterbatasan kemampuan dan juga sumber daya manusianya. Padahal potensi yang dimiliki cukup besar untuk mendorong peningkatan pendapatan bank sampah selain dari sampah non-organik. Maka dari itu dilakukan pengolahan sampah organik dengan 2 model yaitu menggunakan starter atau komposter EM4 dan M21, dari dua proses ini ternyata menghasilkan kompos dalam waktu yang bersamaan, tidak ada yang lebih cepat yaitu sama-sama membutuhkan waktu 30 hari kalender.

Kata Kunci: sampah organik, bank sampah, kompos

How to Cite: Widayat, P., \& Pahlawan, R. (2020). Pengolahan Sampah Organik Bank Sampah Pematang Pudu Bersih Kecamatan Mandau Kabupaten Bengkalis. Prima Abdika: Jurnal Pengabdian Masyarakat, 1(4), $144-151$. https://doi.org/10.37478/abdika.v1i4.1308

cc) (7) (2) Copyright (c) 2021 Prama Widayat, Ryan Pahlawan. This work is licensed undera Creative Commons Attribution-ShareAlike 4.0 International License.

\section{Pendahuluan}

Kecamatan Mandau merupakan salah satu kecamatan yang cukup padat penduduk di Kabupaten Bengkalis, dimana terdapat sebuah Bank Sampah Pematang Pudu Bersih yang berada pada kelurahan pematang pudu dengan jumlah penduduk 29.986 jiwa yang terdiri dari 17 RW dan 95 RT dengan luas wilayah $25 \mathrm{KM}^{2}$. Bank sampah ini berdiri sejak 2015 yang menampung sampah non-organik seperti botol, plastik, kertas dan karton dengan beragam jenis. Namun sejauh ini belum terlalu signifikan keterlibatan masyarakat yang aktif menabung sampah, terlihat dari hanya 643 nasabah yang menabung di bank sampah per Januari 2020 dari total 29.986 jiwa yang ada dikelurahan pematang pudu, jika kita anggap 50\% dewasa berarti ada 14.000 jiwa yang potensi menjadi nasabah bank sampah, artinya baru 4,5\% saja yang tertarik menabung sampah di bank sampah. 
Sejak berdirinya tahun 2015 bank sampah ini sudah berbagai cara dilakukan untuk menarik warga agar mau menabung sampah di bank sampah, sehingga lingkungan bisa menjadi lebih bersih dan warga juga mendapatkan pendapatan dari hasil menabung sampah, kemudian setiap hari kamis di Kecamatan Mandau dilakukan gerakan kamis bersih dimana digilir setiap kelurahan untuk melakuka kegiatan bersig-bersih, nantinya sampah yang terkumpul dibawa ke bank sampah. Kegiatan ini sudah berlangsung lebih dari 1 (satu) tahun dengan tujuan terus mengenalkan bank sampah bukan hanya untuk kelurahan pematang pudu tetapi juga Kecamatan Mandau secara keseluruhan.

Selain kegiatan tersebut, juga dilakukan pendekatan dengan sekolahsekolah yang ada di Kecamatan Mandau mulai dari tingkat TK hingga SMA, kegiatan ini seperti pemanfaatan sampah menjadi kerajinan sehingga para siswa tertarik. Sehingga sebagian besar nabasah yang ada merupakan para siswa dan untuk kalangan masyarakat umum masih sangat terbatas. Belum terjalinnya kemitraan dimulai dari RT, RW, Pemuda-pemudi karang taruna, ibu-ibu PKK sehingga kesadaran masyarakat untuk menabung sampah juga menjadi sangat minim karena mereka lebih tertarik membakar sampah daripada mengumpulkannya dan ini sangat menyusahkan bagi sebagian warga.

Saat ini lokasi penampungan sampah yang ada dikecamatan Mandau juga semakin terbatas dan dalam jangka waktu 5 (lima) tahun kedepan mungkin sangat sulit mencari lahan untuk menampung sampah, dan hal ini tentunya jika dibiarkan berlarut-larut akan menjadi masalah kemudian hari. Menjadikan Bank Sampah PPB untuk solusi mengelola sampah sudah sangat perlu, apalagi ini satu-satunya bank sampah yang ada di Kecamatan Mandau. Dimana terdapat 11 kelurahan yang ada di Kecamatan Mandau :

\begin{tabular}{clr} 
Tabel & 1. Data Penduduk per Kelurahan di Kecamatan Mandau \\
\hline No & \multicolumn{1}{c}{ Kelurahan } & Penduduk \\
\hline 1 & Air Jamban & 49.223 \\
2 & Babussalam & 17.945 \\
3 & Balik Alam & 10.327 \\
4 & Batang Serosa & 3.328 \\
5 & Duri Barat & 17.176 \\
6 & Duri Timur & 10.024 \\
7 & Gajah Sakti & 14.444 \\
8 & Pematang Pudu & 29.986 \\
9 & Talang Mandi & 22.396 \\
10 & Harapan Baru & 5.822 \\
11 & Bathin Betuah & 4.317 \\
\hline & Total & 184.988 \\
\hline
\end{tabular}

Dari jumlah 184.988 jiwa yang ada di Kecamatan Mandau, jika 1 orang menghasilkan 1 kilogram sampah maka dalam satu hari ada 184.988 kilogram sampah yang dihasilkan dalam satu kecamatan. Maka dari itu peran bank sampah disini harus semakin diperluas kepada masyarakat. Ini beum termasuk sampah organik seperti daun-daunan, kulit buah-buahan, potongan sayur dan lainnya, walaupun ini akan hancur sendiri didalam tanah tetapi jika masih bisa diolah dimanfaatkan menjadi produk yang bernilai ekonomis maka akan menambah pendapatan untuk bank sampah. 
Pada dasarnya sampah organik ini mudah terurai tetapi sebelum diuraikan didalam tanah maka akan mengalami pembusukan dan tidak ada nilai ekonomisnya, tetapi jika ini diolah dan dikemas dengan baik maka akan menjadi produk yang memiliki nilai jual dimata masyarakat, mengingat kebutuhan pupuk organik di Riau ini masih disuplay dari Medan karena produsen Riau hanya mampu memenuhi pasar sekitar 25\% sampai dengan 40\% saja dari kebutuhan kompos Riau. Dimana tahun 2020 datang permintaan 100 Ton pupuk kompos untuk lahan Sawit kepada Bank Sampah Pematang Pudu Bersih tetapi mereka tidak punya produk tersebut. Dari sinilah muncul keinginan untuk memproduksi pupuk kompos untuk memenuhi permintaan perkebunan, kedepan kebutuhan ini akan terus meningkat seiring penambahan lahan sawit dan juga kesadaran petani untuk menjaga kelestarian lingkungan dan juga meminimalkan biaya operasional.

\section{Metode Pelaksanaan}

Dalam rangka mencapai tujuan yang tercantum diatas, maka pelaksanaan kegiatan pengabdian pada masyarakat ini dilakukan dengan metode yang sistematis. Pelaksanaan kegiatan dimulai dengan sharing pengalaman tentang konsep bank sampah selanjutnya praktik pengolahan sampah organik, dengan langkah-langkah sebagai berikut :

1. Sharing tentang bahaya sampah organik bagi kesehatan lingkungan:

a) Mengenal sampah organik yang bisa dibuat kompos

b) Keuntungan menggunakan pupuk kompos

2. Memberikan praktek pengolahan sampah organik :

a) Memisahkan sampah organik dengan minyak, karena jika sudah kena minyak maka ini kurang baik. Sebaiknya yang sudah kena minyak goreng dipisahkan pada tempat tertentu.

b) Menyediakan bahan komposter yaitu EM3 dan M21, dimana ini akan menjadi 2 model ujicoba dari 2 komposter tersebut.

c) Membuat pupuk kompos

\section{Hasil dan Pembahasan}

Pada Gambar 1 di bawah ini adalah bahan-bahan yang digunakan untuk pembuatan kompos ini adalah kulit nenas, kulit mangga, kulit pisang, rumput, batang pisang, kotoran hewan (kohe) dan EM4 (sebagai bakteri pengurai sampah), semuanya diaduk menjadi satu dan harus merata.

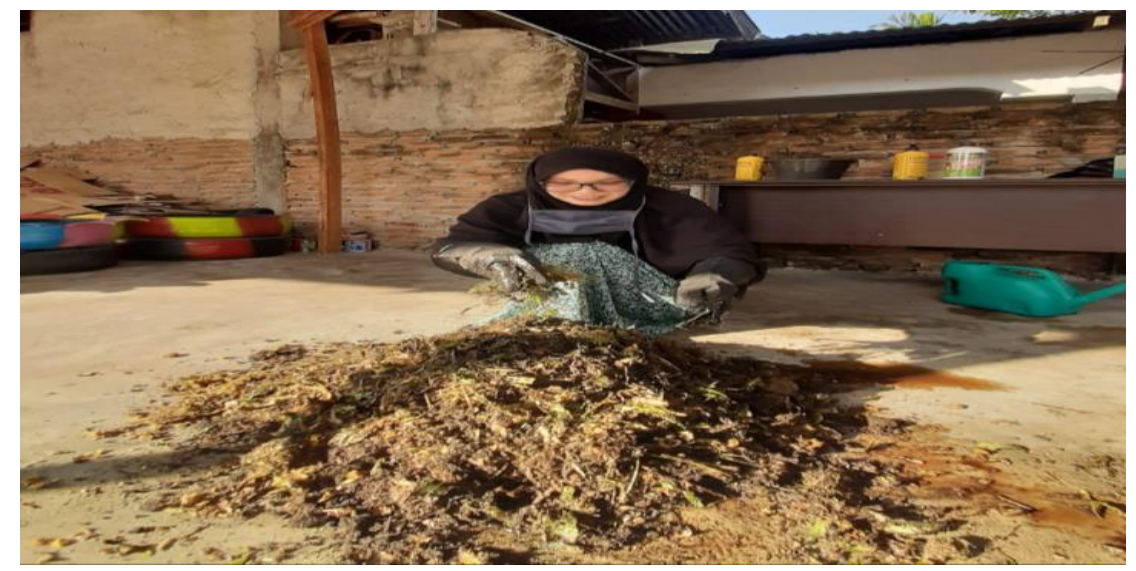

Gambar 1. Bahan sampah organik yang sudah dicacah 
Pada Gambar 2 di bawah ini adalah proses pengadukan semua bahan yang ada pada Gambar 1 diatas tetapi bedanya ini menggunakan M21, semua harus merata agar proses penguraian nantinya berjalan dengan baik dan prosesnya bisa lebih cepat. Jadi terdapat 2 bakterin pengurai yang digunakan untuk melihat, mana yang lebiih cepat nanti prosesnya. Jika pada lazimnya ini berlangsung selama 30 hari

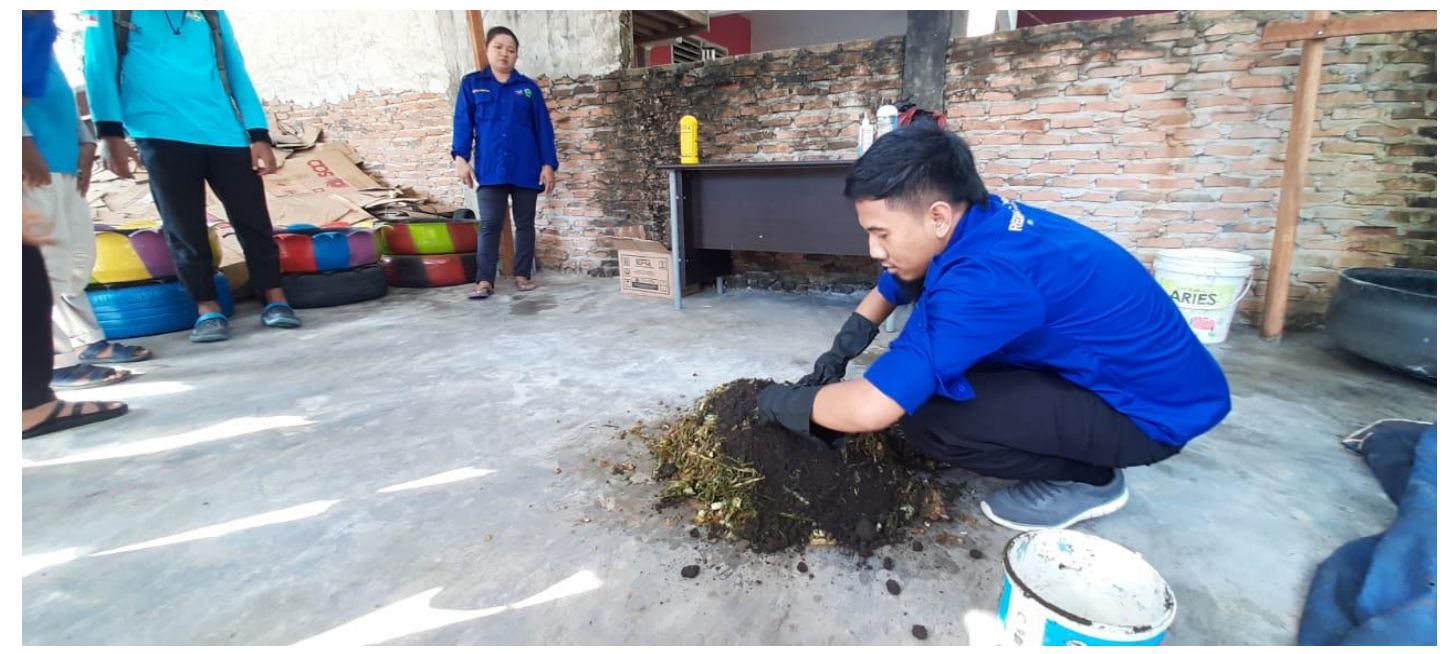

Gambar 2. Proses pengadukan bahan

Setelah berjalan selama 14 hari kalender maka sebagian sampah organik sudah mulai menjadi kompor tetapi belum sempurna, seperti yang terlihat pada Gambar 3.

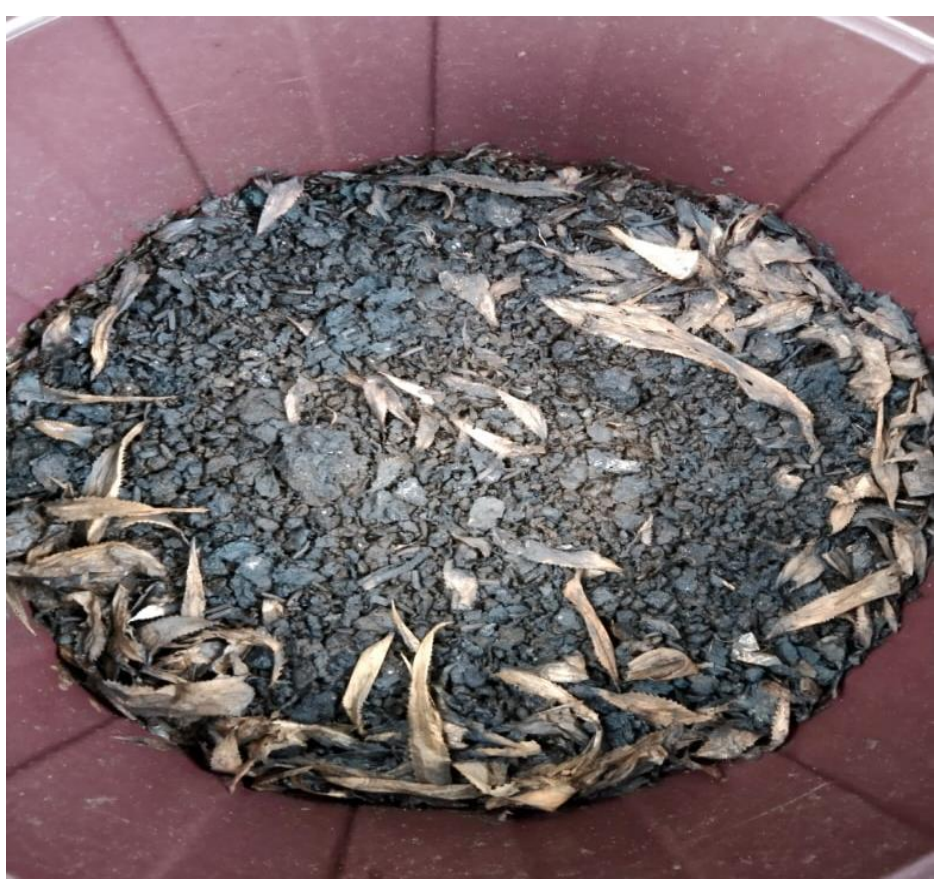

Gambar 3. Kompos setengah jadi

Memasuki hari ke 14 belas maka sebagian sampah organik tersebut sudah menjadi tanah atau kompos, ini menandakan bahwa proses penguraian sudah berjalan dengan baik karena bakteri pengurainya berjalan sesuai dengan tugasnya yaitu mengurai sampah-sampah organi tersebut. Jangan sampah 
proses ini terganggu seperti kena air hujan, ataupun dibiarkan terbuka begitu saja karena selama proses ini dibutuhkan panas maka dari itu perlu ditutup dengan terpal atau dengan tutup lainnya agar terhindar dari cahaya matahari langsung dan air hujan.

Ketika sampah organik tadi sudah dicacah maka proses penguraian akan berjalan dengan cepat selama 30 hari tetapi jika tidak dicacah, ini akan membutuhkan waktu hingga 90 hari atau 150 hari kalender tergantu keras atau tidaknya bahan organik tersebut. Semakin lunak dan kecil potongan sampah organik maka akan mempermudah proses penguraian yang dilakukan oleh bakteri dari EM4 (Nur, 2016) dan M21 yang disebut komposter (Mardwita, 2019).

Setelah melalui waktu selama 30 hari kalender maka hasil yang diperoleh adalah seperti pada Gambar 4 dibawah ini.

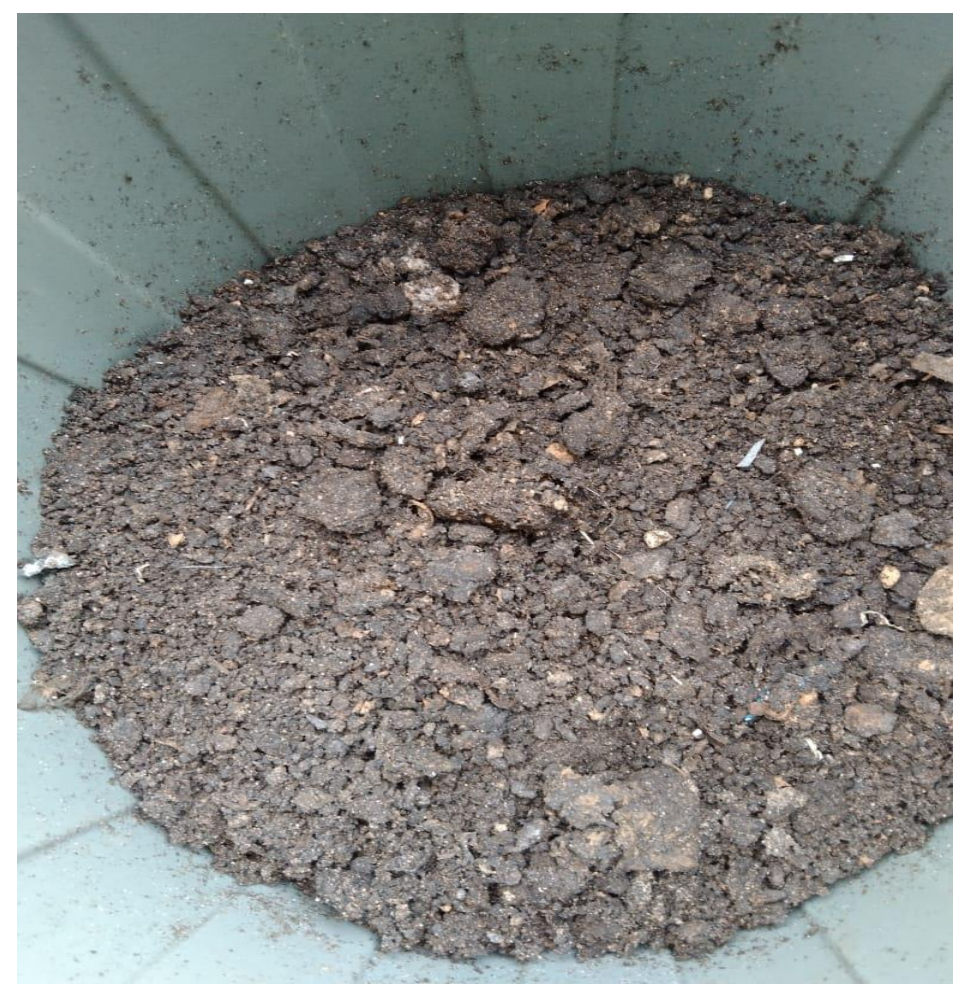

Gambar 4. Pupuk kompos yang sudah jadi

Selama proses pembuatan kompos maka dibutuhkan kesabaran dan setiap minggu perlu dilakukan pengecekan dan pengadukan, agar bagian bawah dipindahkan kebagian atas dengan tujuan meratakan adukan sampah organik. Daripada sampah dibuang ataupun dibakar maka lebih baik dimanfaatkan seperti ini, pupuk kompos ini bisa digunakan untuk bunga yang dipelihara dipekarangan, tanaman pertanian dan perkebunan.

Dengan adanya panduan untuk pembuatan pupuk kompos ini maka dari ibu-ibu PKK ynag sudah mengikuti pelatihan ini bisa menerapkannya dirumah dan dibagi ilmunya dengan warga mereka, karena selama mengikut pelatihan pembuatan pupuk kompos ini mereka sangat antusias dalam bertanya. Setelah berjalan 30 hari ini karena antara EM4 dan M21 sama-sama 
menghasilkan pupuk kompos dan tidak ada yang lebih cepat, jangka waktunya sama-sama 30 hari kalender untuk membuat pupuk kompos ini.

Pentingnya dilakukan penyuluhan dan bimbingan dalam pembuatan kompos untuk memberikan pemahaman kepada masyarakat (Afriani, 2019; Cundari, 2019; Ghufron, 2017), dari bahan-bahan organik (Dahlianah, 2015; Ekawandani, 2019; Gunawan, 2019; Gunam, 2007; Sekarsari, 2020). Butuh strategi dalam pengolahan sampah organik untuk skala kelurahan (Marleni, 2015; Noviana, 2020) karena pengelolan sampah organik ini merupakan salah satu program kampung iklim atau disebut proklim (Rachmawati, 2019; Widayat, 2019).

Selain sampah yang ada dikawasan perumahan, juga terdapat sampah organik yang ada dipasar yang punya nilai ekonomi cukup tinggi (Rahayu, 2013; Widayat, 2021) artinya pengolahan sampah organik menjadi kompos sebagai bagian pemberdayaan masyarakat dalam meningkatkan kapasitas mereka mengelola sampah (Suhastyo, 2017. Virgota, 2020; Widiarti, 2012).

Besarnya potensi sampah organik yang ada dipasar juga bisa dimanfaatkan sebagai media pembuatan maggot (Suciati, 2017), dimana maggot ini bisa menjadi pakan untuk ternak dan juga pakan ikan. Ini sebenarnya menjadi sebuah potensi emas yang belum digarap dan dikelola secara maksimal, padahal sampah organik ini menyumbang 60-70 persen sampah disekitar kita, dimana sekitar 30-40 persennya bisa diolah menjadi kompos namun ini belum mampu dimaksimalkan oleh masyarakat kita karena itulah pentingnya terus dilakukan pelatihan secara berkala untuk penyegaran pemikiran masyarakat melalui bank sampah.

\section{Simpulan dan Tindak Lanjut}

Pentingnya pemanfaatan sampah organik menjadi kompos agar mengurangi beban sampah yang dibuang ke TPA, dengan mengolah setiap rumah setidaknya akan membantu mengurangi 40 persen sampah sejak dari rumah, apalagi manfaat kompos ini dapat digunaan sebagai pupuk tanaman dirumah, tanaman pertanian dan juga perkebunan. Perlu kesadaran individu untuk mengelola sampah organik, dengan demikian muncul kesadaran bersama dimulai dari lingkungan RT kemudian naik tingkat RW dan seterusnya tingkat kelurahan/desa yang pada akhirnya setiap kecamatan akan menjadi sebuah komunitas lokal yang sadar akan pentingnya mengelola sampah organiknya karena sampah organik ini menyumbang $60-70$ persen sampah yang dihasilkan masyarakat.

Pasca kegiatan ini, produksi kompos dari bahan organik akan terus dilakukan, karena tujuannya untuk mengurangi sampah sejak dari rumah, terutama sampah organik. selain untuk mengurangi sampah, juga bisa dijual untuk kebutuhan pupuk organik warga perumahana serta untuk perkebunan kelapa sawit. Kedepan akan terus dilakukan sosialisasi dan pengarahan kepada warga untuk memanfaatkan sampah organik rumah tangga menjadi pupuk kompos yang bisa diolah skala rumahan.

\section{Daftar Pustaka}

Afriani, I. P., Fadilla, N. M., \& Ihsan, T. (2019). Potensi kompos sampah domestik nagari air hitam melalui penyuluhan dan pemanfaatan sampah. Buletin Ilmiah Nagari Membangun, 2(4), 261-267. 
Cundari, L., Arita, S., Komariah, L. N., Agustina, T. E., \& Bahrin, D. (2019). Pelatihan dan pendampingan pengolahan sampah organik menjadi pupuk kompos di desa burai. Jurnal Teknik Kimia, 25(1), 5-12.

Dahlianah, I. (2015). Pemanfaatan Sampah Organik Sebagai Bahan Baku Pupuk Kompos Dan Pengaruhnya Terhadap Tanaman Dantanah. Klorofil: Jurnal Penelitian Ilmu-Ilmu Pertanian, 10(1), 10-13.

Ekawandani, N., \& Kusuma, A. A. (2019). Pengomposan sampah organik (kubis dan kulit pisang) dengan menggunakan EM4. Jurnal TEDC, 12(1), 38-43.

Gunawan, R., Kusmiadi, R., \& Prasetiyono, E. (2015). Studi Pemanfaatan Sampah Organik Sayuran Sawi (Brassica juncea L.) dan Limbah Rajungan (Portunus pelagicus) untuk Pembuatan Kompos Organik Cair. Enviagro: Jurnal Pertanian dan Lingkungan, 8(1), 37-47.

Gunam, W., IB, L. W., Wijaya, I. M. M., Arnata, I., \& Yoga, I. W. S. (2007). Pemanfaatan Sampah Organik Menjadi Pupuk Kompos dengan Bantuan Mikroorganisme di Desa Sibetan Karangasem. Buletin Udayana Mengabdi, $7(2)$.

Ghufron, M. A., Rozak, R. R., Fitrianingsih, A., Matin, M. F., \& Amin, A. K. (2017). Pelatihan pengolahan sampah organik menjadi kompos dengan media keranjang takakura. J-ABDIPAMAS (Jurnal Pengabdian Kepada Masyarakat), 1(1), 98-108.

Mardwita, M., Yusmartini, E. S., Melani, A., Atikah, A., \& Ariani, D. (2019). Pembuatan Kompos Dari Sampah Organik Menjadi Pupuk Cair Dan Pupuk Padat Menggunakan Komposter. Suluh Abdi: Jurnal Ilmiah Pengabdian Kepada Masyarakat, 1(2).

Marleni, Y., Mersyah, R., \& Brata, B. (2012). Strategi Pengelolaan Sampah Rumah Tangga di Kelurahan Kota Medan Kecamatan Kota Manna Kabupaten Bengkulu Selatan. Naturalis: Jurnal Penelitian Pengelolaan Sumber Daya Alam dan Lingkungan, 1(1), 35-40.

Marliani, N. (2015). Pemanfaatan limbah rumah tangga (sampah anorganik) sebagai bentuk implementasi dari pendidikan lingkungan hidup. Formatif: Jurnal Ilmiah Pendidikan MIPA, 4(2).

Noviana, L., \& Sukwika, T. (2020). Pemanfaatan Sampah Organik Sebagai Pupuk Kompos Ramah Lingkungan Di Kelurahan Bhaktijaya Depok. Jurnal Pengabdian UntukMu NegeRI, 4(2), 237-241.

Nur, T., Noor, A. R., \& Elma, M. (2016). Pembuatan pupuk organik cair dari sampah organik rumah tangga dengan bioaktivator EM4 (Effective microorganisms). Konversi, 5(2), 44-51.

Rachmawati, N., Susilawati, S., \& Prihatiningtyas, E. (2019). Pengolahan Sampah Organik Menjadi Kompos Untuk Mendukung Kampung Pro Iklim. Jurnal Pengabdian Al-Ikhlas Universitas Islam Kalimantan Muhammad Arsyad Al Banjary, 4(2).

Rahmawanti, N., \& Dony, N. (2014). Pembuatan Pupuk Organik Berbahan Sampah Organik Rumah Tangga Dengan Penambahan Aktivator EM 4 Di Daerah Kayu Tangi. Ziraa'ah Majalah Imiah Pertanian, 39(1), 1-7. 
Rahayu, D. E., \& Sukmono, Y. (2013). Kajian potensi pemanfaatan sampah organik pasar berdasarkan karakteristiknya (Studi Kasus Pasar Segiri Kota Samarinda). Jurnal Sains \& Teknologi Lingkungan, 5(2), 77-90.

Sekarsari, R. W., Halifah, N., Rahman, T. H., Farida, A. J., Kandi, M. I. A., Nurfadilla, E. A., Fuadah, Z. (2020). Pemanfaatan Sampah Organik Untuk Pengolahan Kompos. Jurnal Pembelajaran Pemberdayaan Masyarakat (JP2M), 1(3), 200-206.

Suciati, R. (2017). Efektifitas media pertumbuhan maggots Hermetia illucens (lalat tentara hitam) sebagai solusi pemanfaatan sampah organik. Biosfer: Jurnal Biologi Dan Pendidikan Biologi, 2(1), 8-13.

Suhastyo, A. A. (2017). Pemberdayaan masyarakat melalui pelatihan pembuatan pupuk kompos. JPPM (Jurnal Pengabdian dan Pemberdayaan Masyarakat), 1(2), 63-68.

Virgota, A., Farista, B., Candri, D. A., Ahyadi, H., \& Jupri, A. (2020). Peningkatan Kapasitas Masyarakat dalam Pengolahan Sampah Sebagai Kompos di Kelurahan Dasan Geres Lombok Timur. Jurnal Pengabdian Magister Pendidikan IPA, 2(2).

Widayat, P. (2019). Pemanfaatan Limbah Plastik Minyak Goreng Pada Panti Asuhan Al Hasanah Desa Pandau Jaya Kecamatan Siak Hulu Kabupaten Kampar. Jurnal Bakti Saintek: Jurnal Pengabdian Masyarakat Bidang Sains dan Teknologi, 3(2), 53-57.

Widayat, P., Hamuddin, B., \& Syofya, H. (2021, March). Waste Bank: Model and Education of Organic and Non Organic Waste Processing in Riau Province. In First International Conference on Science, Technology, Engineering and Industrial Revolution (ICSTEIR 2020) (pp. 372-377). Atlantis Press.

Widiarti, I. W. (2012). Pengelolaan sampah berbasis zero waste skala rumah tangga secara mandiri. Jurnal Sains \& Teknologi Lingkungan, 4(2), 101113. 